\title{
D esafios para a humanização do cuidado em uma unidade de terapia intensiva neonatal cirúrgica
}

\author{
Challenges for humanization of care \\ in a surgical neonatal intensive care unit
}

Denyse T. C. Lamego 1

Suely F. Deslandes 1

M aria Elisabeth L. M oreira 1

1 Instituto Fernandes

Figueira, Fiocruz.

Av. Rui Barbosa 716,

22250-020, Rio de Janeiro RJ.

denyse@iff.fiocruz.br
A bstract This study analyze the environmental cares and the assistance human relations in a surgical neonatal intensive care unit, reflecting about potentialities and obstacles for the promotion of a humanized care. The research, accomplished in an U nit of tertiary level used the method of participant observation focusing, for five months, the human relations professional-baby, professionalparents and mother-baby. Routines contemplating environmental conditions and needs of babies and families, and strategies for noise and brightness reduction were observed, with different levels of effectiveness. The comfort and babies' welfare were provided through body support and non-nutritious suction. These procedures were not systematized and revealed contradictions and ambiguities. The parents' access was encouraged. However, signs of difficulty as fear, insecurity and stress in the parents-babies relationship, pointed out to a need of more care addressed to the family. Attitudes and practices in U nits of Intensive Therapy are permeated by conflicts, negotiations and adaptations to work, constituting a challenge to the construction of a humanized care model, that allies different technologies, respect and welcoming to the patients' and professional needs and the recognition of the cultural logics of the family. Key words Humanizing, Quality of health care, Intensive care, Surgical
Resumo Este estudo analisa cuidados ambientais e relações de atendimento em U nidade de Terapia Intensiva N eonatal Cirúrgica, refletindo sobre potencialidades e obstáculos para promoção de cuidado humanizado. A pesquisa, realizada em uma instituição de nível terciário, utilizou 0 método da observação participante enfocando, por cinco meses, relações profissional-bebê, profissional-responsável e mãe bebê. Foram observadas rotinas contemplando condiç̧ões ambientais enecessi dades de bebês e famílias, e estratégias para redução de ruído e luminosidade, com diferentes níveis de efetividade. 0 consolo e bem-estar dos bebês eram proporcionados por suporte do corpo e uso da sucção não-nutritiva. Tais condutas não eram sistematizadas e revelaram contradições e ambigüidades. 0 acesso dos pais era incentivado, porém sinais de dificuldades como medo, insegurança e estresse na relação pais-bebês, indicaram necessidade de ampliação dos cuidados dirigi dos à família. Posturas e práticas em UTIs N eonatais são permeadas por conflitos, negociações e adaptações ao trabalho, constituindo um desafio à construção de um modelo assistencial humanizado, que alie diferentes tecnologias, respeito e acol himento às necessidades intersubjetivas de pacientes e profissionais e reconhecimento das lógicas culturais das famílias.

Palavras-chave Humanização, Qualidade dos cuidados de saúde, Cuidados intensivos, Cirurgia 


\section{Introdução}

A hospitalização em Unidade de Terapia Intensiva N eonatal (UTIN) introduz o bebê em um ambiente inóspito, onde a exposição intensa a estímulos nociceptivos como 0 estresse e a dor são freqüentes (M oreira et al., 2003). Ruídos, luz intensa e contínua, bem como procedimentos clínicos invasivos são constantes nessa rotina. 0 tratamento al tamente especializado, do qual depende a sobrevivência do bebê, instaura vários desafios à criança e a seus pais. Autores observam interferências nos sistemas de autoregulação dos bebês, que podem até acarretar desequilíbrio nos mecanismos de homeostase e no desenvolvimento cognitivo e da aprendizagem da criança (Whitfield \& Grunau, 2000). Os vínculos familiares também são desafiados, pois os pais podem se sentir amedrontados e/ou "culpados" em ter gerado um bebêfrágil, não se reconhecendo como capazes de oferecer cuidados parentais (Druon, 1999; Braga \& M orsch, 2003). Em uma U nidade de Terapia Intensiva N eonatal Cirúrgica (UTINC), campo do presente estudo, este quadro se agrava, porque a dor, deformidades físicas e cicatrizes são elementos geralmente presentes.

Considerando-se tais desafios, torna-se fecundo repensar as ações em saúde neste âmbito, visando à humanização da assistência em UTIs neonatais.

A humanização representa um conjunto de iniciativas que visa à produção de cuidados em saúde capaz de conciliar a melhor tecnologia disponível com promoção de acolhimento erespeito ético e cultural ao paciente, de espaços de trabal hos favoráveis ao bom exercício técnico e à satisfação dos profissionais de saúde e usuários (Deslandes, 2004; Puccini \& Cecílio, 2004).

Já a humanização do cuidado neonatal preconiza várias ações propostas pelo M inistério da Saúde, baseando-se nas adaptações brasileiras ao M étodo Canguru (Lamy, 2003) para recém-nascidos de baixo peso. Estas são voltadas para o respeito às individualidades, à garantia de tecnologia que permita a segurança do recém-nato e 0 acolhimento ao bebêe sua família, com ênfase no cuidado voltado para o desenvolvimento e psiquismo, buscando facilitar o vínculo mãe-bebê durante a sua permanência no hospital e após a alta (SBP, 2003).

Este estudo visa analisar os cuidados ambientais e as relações de atendimento estabelecidas entre equipe de saúde, bebês hospitalizados e suas famílias em uma UTI neonatal cirúr- gica, refletindo sobre as potencialidades e obstáculos para a promoção de um cuidado humanizado.

\section{Metodologia}

\section{D efinição do método e sujeitos de estudo}

0 estudo ancora-se na perspectiva qualitativa de pesquisa, tomando a observação participante (Becker, 1993) como seu principal método. As relações profissionais e usuários de uma UTINC constituíram a matéria-prima de observação. A pesquisa privilegiou as experiências cotidianas, nas quais os indivíduos adotam uma "atitude natural", isto é, não questionam as estruturas que condicionam suas ações e assim executam as atividades habituais, permitindo-Ihes estocar conhecimentos, integrando simultaneamente a experiência individual e as orientações da cultura (Wagner, 1979).

Foram criados três roteiros observacionais:

a) da relação profissional-bebê (Druon, 1999), voltado para observação da abordagem das situações de estresse no bebê; das intervenções da equipe voltadas para o suporte do corpo do bebê e estabelecimento de vínculo;

b) da relação profissional-mãe/responsável (Lamy et al., 1997; M athelin, 1999), analisando quando os pais eram estimulados a tocar ou permanecer junto de seus bebês ou quando eram desencorajados a fazêlo;

c) da relação mãe bebê (Brazelton, 1988; Klaus \& Kennell, 1993; W innicott, 1996), enfatizando-se a iniciativa e autonomia das mães em tocar e estabelecer comunicação com seus bebês.

Também foram observados os cuidados ambientais relacionados aos ruídos e à iluminação na UTI N eonatal Cirúrgica.

As observações estenderam-se por cinco meses e foram realizadas em horários e plantões diferentes, procurando-se perceber nuances de práticas. Foram realizadas anotações em diário de campo, compondo o acervo de análise. Os sujeitos da pesquisa foram bebês internados, seus acompanhantes e profissionais de saúde. Nesse período foram observadas as relações em torno da assistência de 28 bebês e seus respectivos familiares.

A pesquisa foi aprovada por Comitê de Ética em Pesquisa. Os nomes utilizados neste estudo são fictícios.

Os dados foram analisados à luz do referencial teórico da Psicomotricidade Relacional 
(Ajuriaguerra, s. d.; Aucouturier et al., 1986; Vaivret-Douret, 1997), das teorias do apego e do desenvolvimento emocional do bebê (Brazelton, 1988; Klaus \& Kennell, 1993; W innicott, 1996; Bowlby, 1988) e de estudos realizados em UTIs neonatais, enfocando aspectos como prematuridade e assistência aos pais (Stevens et al., 2000; M athelin, 1999; Whitfield \& Grunau, 2000; M oreira et al., 2003). Buscou-se confrontar as normas e rotinas estabel ecidas e sua aplicação prática no cotidiano da assistência.

\section{0 campo de estudo}

O campo foi uma UTINC pública de uma unidade materno-infantil de nível terciário que atende a recém-nascidos com patologias que requerem intervenções cirúrgicas precoces. Tal serviço foi escolhido por dispor de bons recursos tecnológicos e de pessoal qualificado, condições necessárias à promoção de "cuidados humanizados".

A clientela provém da instituição e de outras unidades do município e outros estados. 0 tempo médio de permanência dos bebês nesta UTI é de aproximadamente 17 dias. A UTINC localiza-se numa enfermaria de cirurgia pediátrica que dispõe de três sal as de cirurgia.

A equipe conta com sete cirurgiões pediátricos, cinco anestesistas, dois pediatras, um nutricionista, um assistente social, um psiquiatra, quatro residentes de cirurgia pediátrica, 11 enfermeiras, duas residentes de enfermagem e 26 técnicas de enfermagem. A capacidade máxima desta unidade é de sete leitos.

\section{Resultados}

\section{Normas e rotinas}

Algumas normas e rotinas gerais afixadas na UTINC dispunham sobre promoção, apoio e manuten ção da amamentação; direitos de informação e esclarecimentos dos pais acerca do estado de saúde de seus filhos e facilitação da relação mãe-bebê.

Quanto ao aleitamento materno, as mães recebiam orientações na UTINC sobre postura e vantagens da amamentação e eram encaminhadas ao Banco de Leite Humano da instituição para realizarem a ordenha e serem orientadas sobre a manutenção da lactação. N ão havia leitos ou alojamento para mães que obtinham al ta da maternidade, mas que estavam amamentan- do. Procurava-se, quando possível, acomodá-las em uma cadeira de descanso na enfermaria de cirurgia. Enquanto a amamentação não era possível, o bebê recebia leite proveniente do Banco, que em geral não era o leite da própria mãe.

Há restrições institucionais estabelecidas quanto ao uso de "chucas" e chupetas, porém, parte da equipe da UTINC mostrou-se favorável ao uso de chupetas nos bebês submetidos a cirurgias, pois estes ficam privados, nos períodos pré e pós-operatórios, do efeito tranqüilizador proporcionado pela sucção não-nutritiva em situações de dor e estresse. Não eram utilizadas chupetas convencionais, mas sim bicos improvisados com luvas esterilizadas, guarnecidas internamente com algodão. Sua administração ficava sob a decisão de cada profissional.

Em geral, o pediatra ou a enfermeira de plantão recebia a família na UTINC, esclarecendo sobre a evolução clínica da criança. No decorrer da internação, orientações sobre cuidados de higiene, amamentação e outros, eram oferecidas, principalmente na preparação para a alta, quando os pais recebiam uma carga mai or de instruções acerca dos cuidados gerais e específicos do bebê e quanto às consultas de acompanhamento. Não foi possível, entretanto, analisar como tais informações eram re-interpretadas pelos pais.

\section{Contexto ambiental da UTIN cirúrgica: os ruídos e a iluminação}

Na UTINC estudada, observou-se a preocupação da equipe em minimizar os efeitos provocados pelo ruído na estabilidade fisiológica e comportamental dos bebês. Os profissionais procuravam falar baixo e manipular com cuidado as portas e painéis das incubadoras. Porém, também se observou que, freqüentemente, objetos eram apoiados sobre as incubadoras. Os ruídos produzidos pelos aparel hos de monitoração eram constantes. Um rádio ficava ligado na UTINC, atendendo às demandas de transformação do ambiente para torná-lo mais agradável aos profissionais, o que dificultava a identificação dos sinais sonoros ( como o choro) emitidos pelo bebê, que poderiam ser indicativos de desconforto ou dor. Por vezes, os profissionais naturalizavam esses ruídos e mesmo os sinais de desorganização fisiológica e corporal dos bebês não eram percebidos.

Janice está na incubadora e começa a chorar. Permanece chorando por aproximadamente 30 minutos, intercalando momentos de desorgani- 
zação tônica e fisiológica, e momentos de cansaço, quando adormece por alguns instantes. Em seguida volta a chorar e a se desorganizar, fazendo disparar o alarme do saturímetro. $\mathrm{N}$ inguém comentou sobre o seu estado, nem se aproximou para ver o que estava acontecendo. (Diário de Campo - M ês 1)

As luzes da UTINC permaneciam sempre acesas e a luminosidade artificial era intensa. A conduta da equipe para reduzir o efeito da luz era colocar um lençol sobre a incubadora, amenizando a interferência desta sobre os ciclos de sono e vigília. Contudo, nos casos em que o bebê apresentava maior instabilidade clínica, este procedimento era suspenso. Priorizava-se a total visibilidade do bebê para melhor vigiar suas respostas.

\section{Contexto relacional}

\section{A relação profissional-bebê}

O bservaram-se abordagens cuidadosas dirigidas à atenção das necessidades de cada bebê. M uitas vezes, contudo, o cuidado era mais automatizado, principal mente quando o profissional encontrava-se submetido a estresse, sobrecarga de trabalho ou urgência de bom desempenho nos procedimentos.

U ma enfermeira diz que veio direto de outro plantão de $12 \mathrm{~h}$ eque emendou dois plantões. Ao realizar os procedimentos com os bebês, fala com eles automaticamente, como se estivesse cumprindo um protocolo. Numa seqüência rápida, diz "oi" para o bebê, chama- o pelo nome, diz para ele o que vai fazer e o que está acontecendo. Em seguida completa: "Você não está entendendo nada disso, não é?" (Diário de Campo - M ês 5)

A disponibilidade e sensibilidade individual dos profissionais, certa acomodação à rotina e o desgaste provocado pelo trabalho em UTI mostraram intervir na relação com o bebê. Ainda, segundo os profissionais, o tipo de vínculo institucional e o tempo de serviço interferiam no comprometimento com o trabalho. A carga horária, controle de faltas e os arranjos informais da jornada de trabal ho foram listados como decisivos para o andamento do serviço, interferindo na produção dos cuidados.

Apesar de a equipe demonstrar conhecimento sobre as necessidades de suporte do corpo para a organização psíquica e fisiológica do bebê, foi mencionado haver resistência de alguns para mudar procedimentos.
Aqui as pessoas são muito resistentes. Eu sempre coloco rolinhos para dar mais proteção ao bebê, mas as pessoas vão e tiram. Tem até estudo sobre isso, mas eu já desisti de falar. (Enfermeira, Diário de Campo - M ês 2)

Observaram-se situações nas quais uma forte ligação foi estabelecida entre o profissional e o bebê, principalmente nos casos mais graves e na ausência materna. Esta vinculação apareceu como elemento fundamental para o bebê reorganizar-se emocional e fisiologicamente após a realização de intervenções clínicas.

Em relação ao manuseio da dor após procedimentos cirúrgicos havia prescrição médica de analgésico.

\section{A relação mãe-bebê}

Observou-se constante preocupação da equipe com a acolhida da mãe, a facilitação de seu acesso e sua permanência no setor. A presença do pai também era incentivada. No primeiro contato pais-bebê, uma pediatra ou enfermeira os recebia e informava sobre o estado de saúde do bebê, aparelhos, terapêutica, a forma de pegar e posicionar para amamentação.

Não havia um espaço para a recepção da família nem local próprio para amamentação. Eram oferecidas cadeiras às mães e, quando possível, os bebês eram colocados em seu colo.

0 pai de Leonardo chega logo após a sua alimentação. Ao chegar, o pai apenas observava seu filho no leito. A enfermeira lhe pergunta se dese ja segurar o bebêe, prontamente, o coloca em seu colo. 0 bebê permanece tranqüilo no colo do pai, dormindo. (Diário de Campo - M ês 4)

Os pais tinham liberdadede acesso àUTINC. Entretanto, observou-se que a equipe incentivava as visitas à tarde, pois, pela manhã realizava-se a maioria dos procedimentos e rotinas. N ão era permitida a entrada de avós nesta UTI, exceto quando os pais não podiam visitar o bebê, conduta justificada pela redução do número de pessoas na unidade e, conseqüentemente, do risco de infecção hospitalar.

À medida que os pais se familiarizavam com a situação e que as relações com a equipe se solidificavam, a autonomia em participar dos cuidados do bebêaumentava.

Enquanto realiza os procedimentos de cuidado em Mateus, Aurora (profissional) conversa com a mãe sobre o nascimento dos filhos, a diferença entre os partos. A mãe de $M$ ateus comenta sobre a facilidade do parto normal, a ausência de dor no parto do filho mais velho e a cesárea de 
M ateus, a dor, o tempo de gestação, etc. Laura conversa animadamente com a enfermeira e, enquanto esta examina e mede a temperatura do bebê, a própria mãetroca sua fralda, incentivada pela enfermeira. (Diário de Campo - M ês 2)

\section{A relação profissional-responsável}

M uitas vezes os pais eram estimulados a tocar e acal mar seus bebês, sendo sua presença valorizada para a formação do vínculo e inclusão nos cuidados.

Todavia, momentos de agravamento do quadro clínico, urgência e necessidade de performance técnica, ou mesmo dificuldades na comunicação entre pais e profissionais, acarretavam interdição da presença dos pais, que eram desencorajados a tocar em seus bebês.

Observou-se que situações de medo e insegurança diante da experiência da hospital ização podiam causar, nos pais, uma dificuldade em se comunicar com a equipe, agravando o temor de tocar no bebê.

Bruno éum bebê de 8 dias, nascido em outro hospital, que está há 3 dias na UTINC. Pergunto aos pais se estão podendo segurá-lo no colo. Respondem que ainda não o pegaram, pois não sabem se podem. A mãe diz que já o tocou, mas não sabe se pode continuar a fazê lo. Pergunto se eles já conversaram com alguém da equipe sobre o estado atual do bebê, e o pai responde que ainda não tiveram nem a curiosidade de perguntar, pois quando Bruno foi internado disseram para não mexer na criança, pois isto poderia "causar problemas". 0 pai diz que ficou com tanto medo, que não o tocou mais desde então. (Diário de Campo - M ês 3)

\section{Discussão}

0 entendimento de que um bebê não existe fora de um contexto familiar tem mudado as relações dentro da UTI. Tais relações se estabelecem antes do nascimento quando se detecta uma patologia, podendo alterar precocemente a interação ou vínculo das famílias com seus bebês. Por isso, a forma de recebê lo na UTI é tão importante. Transformações têm sido realizadas, com ampliação dos cuidados para incluir as famílias e proporcionar maior consolo e o manejo da dor destes bebês (Saunders et al., 2003).

Como já discutido, a exposição a numerosos e repetidos estímulos nocivos podem levar a desorganizações fisiológicas e comportamen- tais. 0 bebê passa, então, a usar suas reservas de energia para auto-regulação, "economizando" ao máximo tal gasto (Stevens et al., 2000; Braga \& M orsch, 2003). Embora as intervenções para diminuir o estresse ambiental possam ser efetivas na promoção de estabilidade fisiológica (Stevens et al., 2000), a natureza nociva do ambiente das UTI não tem sido alterada substancialmente.

M anifestações psicomotoras como as ritmias (Lézine \& Stambak, 1959) são observáveis em bebês com histórico de internação precoce, decorrentes de perturbações dos ritmos exteriores, como ausência de noite-dia, das atividades de maternagem em horas fixas, de períodos de silêncio e ruído, da palavra efiltragem das aferências sensoriais pela incubadora, afetando, sobretudo, as funções posturais e motoras dos bebês.

$\mathrm{Na}$ UTI estudada observou-se uma preocupação primária com o ambiente, embora como uma demanda relacionada à melhoria do ambiente de trabalho, como na questão do rádio ligado.

Segundo Stevens et al. (2000) a diminuição da carga total de estímulos nocivos para os bebês pode ser executada pela redução geral dos níveis de luz e favorecimento das condições de alternar dia e noite, reduzindo níveis de cortisol e freqüência cardíaca, promovendo o aumento do sono, o ganho de peso e o desenvolvimento dos ritmos nos bebês.

Estratégias para diminuição do ruído estavam implementadas na UTI estudada, embora nem sempre cumpridas, tendo sido observado 0 constante apoio de objetos sobre as incubadoras.

Quanto ao ruído das falas, autores observam que este pode apresentar um caráter positivo ou negativo. Permite ao bebê a sua inserção no mundo da linguagem, principalmente quando o som é originário da voz materna, 0 que pode representar um amparo psíquico ao bebê (Braga \& M orsch, 2003). Entretanto, quando havia muitas pessoas na unidade, esta conversa se transformava em um ruído intenso e incômodo, estressando bebês e equipe. Esta justificativa impedia a entrada de outros familiares incluindo os avós, mas não o acesso de profissionais de outros setores em visita aos colegas ali lotados.

As estratégias relacionadas à intensidade de luz eram menos efetivas. A proteção das incubadoras era abandonada em favorecimento das condições de trabal ho dos profissionais, neste caso, maior visibilidade do bebê, ainda que este se encontrasse monitorizado. 
Em relação ao consolo do bebê, observouse na unidade a valorização do uso da chupeta. Embora o hospital siga os dez passos da política pública H ospital Amigo da Criança, que em seu nono passo preconiza o não uso da chupeta, ela era utilizada de forma artesanal.

Revela-se a polêmica e as ambigüidades entre o que é preconizado nas campanhas de amamentação e a interpretação das demandas de cada bebê, especial mente daqueles internados numa UTINC. Alguns estudos sugerem que o uso da chupeta não influencia a amamentação (Collins et al., 2004), o que não é consensual. O M inistério da Saúde reconhece que a sucção não nutritiva em bebês de UTI pode ser viabilizada em alguns casos, principalmente quando a dor estiver envolvida (MS, 2000). Ela pode ser efetiva na redução da dor e do choro em bebês prétermo durante procedimento de punção e colaborar na indução do sono, favorecendo a ativação dos mecanismos de homeostase (Stevens et al., 2000).

0 acesso das famílias é outro ponto importante na discussão dos cuidados humanizados ao recém-nascido (Agman et al., 1999; Druon, 1999; Braga \& M orsch, 2003). Embora não houvesse um ambiente específico para sua permanência, 0 acesso dos pais era incentivado. A presença de outros familiares na UTINC ainda não foi incorporada, evidenciando a necessidade de um cuidado mais ampliado. De certa forma, 0 ambiente (físico e relacional) não era favorável, dificultando, algumas vezes, as possibilidades de relação família-bebê, propiciando o aparecimento de sinais de estresse e medo nesses pais.

Alguns estudos revelam a necessidade de acolhimento e suporte psicológico aos pais, para que eles possam significar mel hor os acontecimentos e sentimentos e ter condições emocionais para superar o trauma da hospitalização e relacionar-se com seus filhos na UTI-N eonatal (Agman et al., 1999; Druon, 1999; M oreira et al., 2003). Segundo Druon (1999), a escuta dos pais beneficia todos os envolvidos, pois ajuda a: evocar o traumático e a fazer a ligação entre o que é vivido realmente e as fantasias; identificar as demandas dos pais em relação aos seus bebês e ao serviço de neonatologia; re forçar os laços com o serviço e aumentar a perspectiva de um acompanhamento (Followup); produzir identificação mãe-bebê; trabalhar de forma interdisciplinar.

\section{Considerações finais}

A UTINC estudada sugere avanços e ambigüidades que podem ser comuns a muitas outras do país. Em geral nota-se uma disposição favorável ao acolhimento das mães e o reconhecimento das necessidades dos bebês.

Revelam-se ambigüidades entre adotar práticas mais flexíveis (uso de sucção não nutritiva, de lençóis sobre as incubadoras) e a retomada das regras vigentes quando o estado de saúde do bebê implicava maior intensidade de avaliação clínica. Em um campo de práticas onde as evidências científicas sustentam atitudes e procedimentos, ações ain da não comprovadas por estudos sistemáticos, vistas como "alternativas", tendem a ser suprimidas nos momentos de incerteza.

I gualmente negociadas são as regras de cuidados ambientais como os ruídos e iluminação. Ainda que conscientes de seus efeitos nocivos, os profissionais também transformam o ambiente para suas próprias necessidades, em um exercício adaptativo das condições de trabalho.

Indica-se o importante papel do profissional como mediador das relações de vínculo entre mães e bebês. Assim, jornadas extensas e desgastantes podem acarretar dificuldades na atenção das necessidades mais sutis do bebê e (inter)subjetivas de sua mãe. Entretanto, os profissionais também têm limites a serem negociados. Sentem-se desconfortáveis na presença das mães quando precisam fazer procedimentos mais invasivos ou em momentos críticos.

Ofertar uma assistência que provenha a melhor tecnologia de saberes, procedimentose equipamentos, conjugada ao acolhimento das necessidades intersubjetivas dos pacientes e dos profissionais e ao reconhecimento das lógicas culturais dos familiares (que permitem a interpretação da hospitalização), é um dos grandes desafios da atenção em saúde. 


\section{Colaboradores}

DTC Lamego trouxe contribuições para a elaboração de roteiros e realização da observação participante no campo estudado, além da análise dos dados e redação do artigo. SF Deslandes contribuiu especificamente para a definição do método da pesquisa, interpretação dos dados e redação do artigo, e M EL M oreira trouxe importantes contribuições da área de neonatologia para a interpretação dos dados, além de colaborar na redação e revisão do artigo.

\section{Referências bibliográficas}

Agman M, Druon C \& Frichet A 1999. Intervenções psicológicas em neonatologia, pp. 17-34. In DB Wanderley (org.). Agora eu era o rei: os entraves da prematuridade. Ed. Ágalma, Salvador.

Ajuriaguerra [ [s.d.]. M anual de Psiquiatria Infantil. Ed. M asson, São Paulo.

Aucouturier B, Darrault I \& Empinet J 1986. A prática psicomotora: reeducação e terapia. Ed. Artes M édicas, Porto Alegre.

Becker HS 1993. M étodos de pesquisa social. Hucitec, São Paulo.

Bowlby J 1988. Cuidados maternos e saúde mental. Ed. $M$ artins Fontes, São Paulo.

Braga NA \& M orsch DS 2003. Os primeiros dias na UTI, pp. 51-68. In M EL M oreira, NA Braga \& DS M orsch (orgs.). Q uando a vida começa diferente: 0 bebê e sua família na UTI N eonatal. Fiocruz, Rio de Janeiro.

Brazelton TB 1988. 0 desenvolvimento do apego. Ed. Artes M édicas, Porto Alegre.

Collins CT, Ryan P, Crowther CA, M CPhee AJ, Paterson S $\&$ Hiller JE 2004. Effect of bottles, cups, and dummies on breast feeding in preterm infants: a randomised controlled trial. British Medical Journal 329(7459):193-198.

Deslandes SF 2004. Análise do discurso oficial sobre humanização da assistência hospitalar. Ciência \& Saúde Coletiva 9(1):7-14.

Druon C 1999. Ajuda ao bebê e aos seus pais em terapia intensiva neonatal, pp. 35-54. In DB Wanderley (org.). A gora eu era o rei: os entraves da prematuridade. Ed. Ágalma, Salvador.

Klaus M \& Kennell J 1993. Pais-bebês: a formação do apego. Ed. Artes M édicas, Porto Alegre.

Lamy Z 2003. M etodologia Canguru: facilitando o encontro entre o bebê e sua família na UTI N eonatal, pp. 141-156. In MEL Moreira, NA Braga \& DS M orsch (orgs.). Q uando a vida começa diferente: 0 bebê e sua família na UTI N eonatal. Fiocruz, Rio de Janeiro.

Lamy Z, Gomes R \& Carvalho M 1997. A percepção de pais sobre a internação de seus filhos em unidade de terapia intensiva neonatal. Jornal de Pediatria 5 (73):293-298.

Lézine I \& Stambak M 1959. Quelques problème d'adaptation de jeune enfant en fonction de son type moteur et du régime éducatif. Ed. Enfance, Paris.
M athelin C 1999. Da pulsão de morte ao desejo de vida, ou as vicissitudes de uma terapia intensiva, pp. 6179. In DB Wanderley (org.). A gora eu era o rei: os entraves da prematuridade. Ed. Ágalma, Salvador.

Ministério da Saúde [ 1 ㅇ de agosto de 2000]. Razões médico-fonoaudiológicas aceitáveis para o uso de chupetas em recém-nascidos internados em UTI neonatal. Ministério da Saúde, Brasília.

M oreira M EL, Rodrigues MA, Braga NA \& M orsch DS 2003. Conhecendo uma UTI neonatal, pp. 29-42. In MEL Moreira, NA Braga \& DS Morsch (orgs.). Q uando a vida começa diferente: o bebê e sua família na UTI N eonatal. Fiocruz, Rio de Janeiro.

Puccini PT \& Cecílio LCO 2004. A humanização dos serviços e o direito à saúde. Cadernos de Saúde Pública 20(5):1342-1353.

Saunders RP, Abraham M R, Crosby MJ, Thomas K \& Edwards WH 2003. Evaluation and development of potentially better practices for improving family-centered care in neonatal intensive care units. Pediatrics 111(4 Pt 2):e437-449.

SBP - Sociedade Brasileira de Pediatria 2003. Os 10 passos para a atenção hospitalar humanizada à criança $\mathrm{e}$ ao adolescente. SBP, Rio de Janeiro.

Stevens B, Gibbins S \& Frank LS 2000. Treatment of pain in the neonatal intensive care unit. Pediatric Clinics of N orth America 47(3):633-650.

Vaivret-Douret L 1997. Intervention précoce en psichomotricité aupriès d'enfant hospitalisés en unités intensifs et en néonatalité. N europsychiatrie de l'Enfance et de l'Adolescence 45(4-5):190-208.

Wagner HR 1979. Introdução, pp. 3-52. In A Schutz. Fenomenologia e relações sociais. Ed. Zahar, Rio de Janeiro.

Whitfield M F \& Grunau RE 2000. Behavior, pain perception and the extremely low-birth weight survivor. Clinics of Perinatology 27(2):363-379.

Winnicott DW 1996. Os bebês e suas mães. Ed. M artins Fontes, São Paulo.

Artigo apresentado em 17/04/2005

Aprovado em 4/05/2005

Versão final apresentada em 12/05/2005 